\title{
Paying attention to emotion: An fMRI investigation of cognitive and emotional Stroop tasks
}

\author{
REBECCA J. COMPTON \\ Haverford College, Haverford, Pennsylvania \\ MARIE T. BANICH \\ University of Colorado, Boulder, Colorado
}

and

\begin{abstract}
APRAJITA MOHANTY, MICHAEL P. MILHAM, JOHN HERRINGTON, GREGORY A. MILLER, PAIGE E. SCALF, ANDREW WEBB, and WENDY HELLER

University of Illinois at Urbana-Champaign, Champaign, Illinois
\end{abstract}

\begin{abstract}
In this research, we investigated the degree to which brain systems involved in ignoring emotionally salient information differ from those involved in ignoring nonemotional information. The design allowed examination of regional brain activity, using fMRI during color-word and emotional Stroop tasks. Twelve participants indicated the color of words while ignoring word meaning in conditions in which neutral words were contrasted to emotionally negative, emotionally positive, and incongruent color words. Dorsolateral frontal lobe activity was increased by both negative and incongruent color words, indicating a common system for maintaining an attentional set in the presence of salient distractors. In posterior regions of the brain, activity depended on the nature of the information to be ignored. Ignoring color-incongruent words increased left parietal activity and decreased parahippocampal gyrus activity, whereas ignoring negative emotional words increased bilateral occipito-temporal activity and decreased amygdala activity. The results indicate that emotion and attention are intimately related via a network of regions that monitor for salient information, maintain attention on the task, suppress irrelevant information, and select appropriate responses.
\end{abstract}

Cognition and emotion are intricately intertwined, because individuals orient toward, perceive, and interpret external stimuli in the context of their motivational and behavioral significance. Information associated with danger, for example, may be especially likely to capture or engage attention. Behavioral studies have confirmed that people are slower to shift attention away from words with emotional significance (e.g., Stormark, Nordby, \& Hugdahl, 1995), supporting the notion that emotional factors may have an important influence on the deployment and operation of attention. How emotional factors

R.J.C. was supported by NIMH Institutional National Research Service Award MH19554, and this research was supported by the Beckman Institute at the University of Illinois at Urbana-Champaign and by NIH Grants R01 MH61358 and R21 DA14111. The research was carried out in collaboration with Carle Clinic Association in Urbana, IL. The authors gratefully acknowledge Vikram Barad, Daniel Gullett, Lawrence Hubert, Holly Tracy, and Tracey Wszalek for technical assistance and Eric Claus and Derrick Wirtz for assistance in data collection. Correspondence concerning this article may be addressed to R. J. Compton, Department of Psychology, Haverford College, 370 Lancaster Avenue, Haverford, PA 19041 (e-mail: rcompton@ haverford.edu) or to M. T. Banich, Department of Psychology, University of Colorado, UCB 345, Boulder, CO 80309 (e-mail: mbanich@psych.colorado.edu). modulate activity in brain regions involved in attention is thus an important question. To address this issue, in the present investigation, we examined the impact of emotional salience on activity in neural systems of attention by examining the influence of emotional and nonemotional distractors on brain activation.

One viewpoint regarding the relationship between emotion and cognition holds that reciprocal brain regions are involved in emotional versus cognitive tasks. For example, Drevets and Raichle (1998) found, across a wide range of PET studies, that a constellation of regions, including the dorsolateral prefrontal cortex (DLPFC) and the dorsal anterior cingulate cortex (ACC), was consistently more active during cognitive tasks but was less active during tasks with an emotional component. A complementary constellation of regions, including the orbitofrontal cortex (OFC), the ventral ACC, and the amygdala, was more active for emotional tasks and less active for nonemotional tasks. The authors interpreted these findings as supporting a reciprocity, or tradeoff, between cognition and emotion, such that as activity increases in cognitive regions, it decreases in emotional regions and vice versa.

Although the reciprocity conception of cognition and emotion may be a useful heuristic for conceptualizing 
some functions or neural systems, other systems may be less easily classified as cognitive or emotional, because they subserve functions that are crucial to both cognition and emotion (e.g., Gray, Braver, \& Raichle, 2002; Simpson, Drevets, Snyder, Gusnard, \& Raichle, 2001). Thus, an alternative to the cognition-emotion reciprocity position is that tasks typically classified as cognitive and emotional may at times rely on common, overlapping neural systems, due to their common, overlapping computational and behavioral functions. Precisely because of the overlap in cognitive and emotional functions implemented by many brain regions, we have argued that patterns of brain activity associated with changes in emotional state provide a powerful tool for understanding the cognitive characteristics of emotional disorders (e.g., Heller \& Nitschke, 1997; Miller, 1996; Nitschke, Heller, \& Miller, 2000).

One way to evaluate the extent of neural overlap between cognitive and emotional functions is to examine how emotion modulates activity in brain regions known to participate in certain cognitive functions (for a similar approach, see Lane, Chua, \& Dolan, 1999; Simpson et al., 2000). In the present study, we investigated whether selective attention in the presence of distracting emotional information involves the same neural systems as those identified in studies of selective attention that were not designed to engage emotional processes. As a measure of selective attention, we employed the color-word Stroop task, often considered the "gold standard" of selective attention tasks (MacLeod, 1992). In this task, the individual identifies the ink color of a word while ignoring the word's meaning. Selective attention is required because word reading is relatively automatic, as compared with identifying ink colors, making word meaning difficult to ignore (see MacLeod, 1991, 1992, for reviews). Selection demands are especially great on incongruent trials, in which the word names a color that conflicts with the ink in which it is printed (e.g., the word blue in red ink), as compared with neutral trials, in which the word is not related to color (e.g., the word late in red ink).

Researchers have recently developed an emotional variant of the Stroop task in order to examine selective attention in the presence of emotional distractors (Dalgleish \& Watts, 1990; Williams, Mathews, \& MacLeod, 1996). The emotional Stroop task is similar to the colorword Stroop task, in that the primary task is to identify the ink color of a word as quickly as possible while ignoring the word's meaning. Thus, for both emotional and color-word Stroop tasks, the task-relevant attribute of the stimulus is the ink color. However, in the emotional Stroop task, the meaning of the distractor word is either neutral or emotional, whereas in the standard Stroop task, the meaning of the distractor word is color related. Although the emotional Stroop task is not completely Stroop-like, because it presents no direct conflict between the relevant and the irrelevant stimulus dimensions, the term emotional Stroop has been widely used in the behavioral literature because of the surface similarities between these color-naming tasks. Indeed, research has demonstrated that individuals are slower to identify the ink color of emotionally significant words, presumably because the word meaning diverts attention from the primary color-naming task (Williams et al., 1996). Although most often used as a measure of attentional bias toward threat in clinically anxious individuals (e.g., Mathews \& MacLeod, 1985; Mogg, Mathews, \& Weinman, 1989), the emotional Stroop effect (i.e., the slowing of responses when words are emotional) has been demonstrated in nonclinical groups as well (e.g., McKenna \& Sharma, 1995).

To the degree that both the emotional Stroop and the color-word Stroop depend on similar attentional mechanisms, similar brain regions should be active in both tasks. In particular, both tasks involve selectively attending to color information while suppressing responses to distracting word information. In contrast, to the degree that the two tasks involve unique task demands, we would expect different regions to be involved.

\section{Models of Attentional Networks Involved in the Color-Word Stroop}

Research on the color-word Stroop task provides a heuristic for examining the contributions of emotional and nonemotional information to attentional regulation. Although it is typically thought that most attentional modulation of brain activation occurs to information that is task relevant, recent research indicates that attentional demand also modulates activity of brain regions responsible for processing task-irrelevant information (Banich, Milham, Atchley, Cohen, Webb, Wszalek, Kramer, Liang, Wright, et al., 2000; Banich et al., 2001). Because of the brain's sensitivity to task-irrelevant information, the emotional Stroop paradigm-in which task-irrelevant emotional information is manipulated-provides a means for examining how emotional information can influence or modulate brain regions involved in attentional control.

Numerous brain-imaging studies have identified a network of brain structures, including regions of the DLPFC, the ACC, and the parietal cortex, whose activity is increased in incongruent color-word conditions, as compared with neutral word conditions, of the Stroop task (e.g., Banich, Milham, Atchley, Cohen, Webb, Wszalek, Kramer, Liang, Barad, et al., 2000; Banich, Milham, Atchley, Cohen, Webb, Wszalek, Kramer, Liang, Wright, et al., 2000; Banich et al., 2001; Bench et al., 1993; Carter, Mintun, \& Cohen, 1995; Milham et al., 2001; Milham et al., 2002; Pardo, Pardo, Janer, \& Raichle, 1990; Petersen et al., 1999). In a series of experiments, Banich, Milham, Atchley, Cohen, Webb, Wszalek, Kramer, Liang, Wright, et al. (2000; Banich, Milham, Atchley, Cohen, Webb, Wszalek, Kramer, Liang, Barad, et al., 2000; Banich et al., 2001; Milham et al., 2001; Milham et al., 2002) have demonstrated that some brain regions are more responsive to the task-relevant dimension of the 
stimulus (the information that the individual is supposed to focus on, such as the ink color in the standard Stroop task), whereas other brain regions show modulation as a function of the task-irrelevant dimensions of the stimulus (i.e., aspects of the stimulus that the individual is supposed to ignore, such as the word information in the standard Stroop task). Specifically, Banich, Milham, Atchley, Cohen, Webb, Wszalek, Kramer, Liang, Wright, et al. (2000, Banich et al., 2001; Milham et al., 2002) have found that activity in the DLPFC (in the inferior and middle frontal gyrus; BAs 9, 44, and 46) is associated with the need to maintain an attentional set that selects task-relevant information in the face of more salient distracting information. Research by other investigators has also demonstrated the importance of the DLPFC in filtering task-relevant from irrelevant attributes (e.g., Shimamura, 2000; Thompson-Schill, D'Esposito, Aguirre, \& Farah, 1997).

In contrast, activity in posterior regions is modulated by the nature of task-irrelevant dimensions of the stimulus (Banich, Milham, Atchley, Cohen, Webb, Wszalek, Kramer, Liang, Wright, et al., 2000; Banich et al., 2001; Milham et al., 2002). For example, one study (Banich, Milham, Atchley, Cohen, Webb, Wszalek, Kramer, Liang, Wright, et al., 2000, Experiment 2) kept the task-relevant attribute constant, asking participants to identify an ink color, while manipulating whether the task-irrelevant attribute was a word or a line drawing of an object. On incongruent trials, the task-irrelevant attribute conflicted with the ink color (e.g., the word blue in red or a drawing of a red frog), whereas on neutral trials it did not (e.g., the word lot in red or a drawing of a red car). Posterior activation differed for these two conditions, with brain regions involved in processing words exhibiting greater activity for the color-word task and brain regions involved in object processing exhibiting greater activity for the color-object task.

This model of the neural mechanisms involved in attentional control predicts that activity produced by the emotional Stroop should be similar to that produced by the color-word Stroop in prefrontal regions, but not in posterior regions, of the brain. Attentionally demanding emotion words and incongruent color words should increase activity in similar DLPFC regions, because both involve the need to maintain a selective focus on the ink color (the task-relevant dimension) in the presence of salient distractors. In contrast, the emotional Stroop task should not modulate activity in posterior brain regions in the same way as the color-word Stroop task, since the two tasks differ from one another in the nature of the taskirrelevant stimulus dimension. That is, the task-irrelevant information in the emotional Stroop-specifically, the emotional meaning-is not related to the color identification task in the same way as is incongruent color information. Thus, the same set of posterior regions should not be engaged for the emotional and the color-word Stroop.

Although prior research indicated that parietal lobe activity for the color-word Stroop is more strongly mod- ulated within the left than within the right hemisphere (Banich, Milham, Atchley, Cohen, Webb, Wszalek, Kramer, Liang, Wright, et al., 2000; Banich et al., 2001), we predicted that the posterior right hemisphere should become more active in the presence of emotion words. This prediction was based on the hypothesis that this region, also known to play a role in vigilance, monitoring, and spatial attention, embodies an emotional surveillance system that becomes engaged in the presence of emotionally salient information (Bear, 1983; Nitschke et al., 2000). In a divided visual field study of the emotional Stroop effect, we found that emotional words reduced a left-hemisphere advantage in color naming, suggesting increased right-hemisphere activity (Compton, Heller, Banich, Palmieri, \& Miller, 2000). These results concur with other behavioral laterality studies that have indicated that the right hemisphere becomes more active in response to emotional conditions, particularly in response to threat (e.g., Asbjornsen, Hugdahl, \& Bryden, 1992; Gruzelier \& Phelan, 1991; Van Strien \& Heijt, 1995; Van Strien \& Morpurgo, 1992). The divided visual field technique, in which participants respond to words flashed briefly to either the left or the right visual field, can determine only relative activity of the right versus the left hemisphere, however. The present neuroimaging study can thus better localize which posterior righthemisphere regions appear to be especially involved in responding to emotional information in this attentional paradigm.

\section{Previous Neuroimaging Studies of the Emotional Stroop Task}

Although several prior neuroimaging studies have provided intriguing clues regarding the neural systems involved in the emotional Stroop, the existing studies have tended to focus on a small set of brain regions and have produced conflicting results. Isenberg et al. (1999) reported bilateral amygdala activation in an fMRI study of the emotional Stroop task in which threatening words were used. However, the study focused primarily on this a priori region of interest and did not examine the entire range of brain structures potentially involved in attentional control in this task. Furthermore, Isenberg et al. did not include a color-word Stroop task for comparison, so it is difficult to assess the extent to which similar attentional networks would be involved in an emotional Stroop task and a color-word Stroop task. In an fMRI study, Whalen et al. (1998) found that performing an emotional Stroop task engaged a ventral subregion of the ACC, whereas a nonemotional counting Stroop task activated a more dorsal region of the ACC, supporting the proposal that the ACC is composed of subregions that are differentially involved in cognitive versus emotional tasks (Bush, Luu, \& Posner, 2000; Devinsky, Morrell, \& Vogt, 1995; Drevets \& Raichle, 1998). In contrast to Whalen et al.'s findings, prior PET studies showed that an emotional Stroop task activated the same left-midcingulate region as a color-word Stroop task, although to a lesser 
extent (George et al., 1994), or that an emotional Stroop task did not produce any ACC activation (George et al., 1997). Methodological differences (e.g., in practice and response-related variables) may account for these inconsistent findings. In any case, further investigation of the brain regions involved in the emotional Stroop task is warranted.

\section{Role of Emotional Valence and Arousal in the Emotional Stroop Task}

Psychophysiological data and theory indicate that the valence and arousal dimensions of emotion may be associated with different neural systems. Valence indexes the positive versus the negative meaning of a stimulus, whereas arousal level, conceptually orthogonal to the valence dimension, indexes emotional intensity (for reviews, see Larsen \& Diener, 1992; Russell, 1978, 1980; Watson, Wiese, Vaidya, \& Tellegen, 1999). Valence and arousal dimensions are associated with different physiological correlates in the peripheral nervous system, such as skin conductance, heart rate, and facial muscle activity (e.g., Lang, Bradley, \& Cuthbert, 1990; Lang, Greenwald, Bradley, \& Hamm, 1993), and neuropsychological theories of emotional experience have also distinguished between valence and arousal (e.g., Heller, 1993; Heller, Nitschke, \& Lindsay, 1997; Nitschke, Heller, Palmieri, \& Miller, 1999).

Some behavioral studies of the emotional Stroop effect have found that interference is more reliably obtained with negative than with positive emotion words (e.g., McKenna \& Sharma, 1995). From an adaptive point of view, it may be especially crucial for signals of danger to capture attention. Signals of sadness, calmness, or pleasure may not have the same immediate survival relevance that would warrant a redirection of attention. However, because prior behavioral studies have typically confounded valence and arousal-for example, by comparing high-arousal negative words (e.g., danger) with low-arousal positive words (e.g., peace)-more systematic research is needed to determine the roles of stimulus valence and arousal level in the emotional Stroop effect.

Existing neuroimaging studies of the emotional Stroop effect have employed only negatively valenced words and have not separately examined the influence of arousal level (George et al., 1994; George et al., 1997; Isenberg et al., 1999; Whalen et al., 1998). To examine the neural concomitants of these dimensions of emotion more systematically, in the present investigation, the valence and arousal of emotional Stroop stimuli were independently manipulated. We predicted that highly arousing negative emotional words would be most likely to capture attention, resulting in greater behavioral Stroop interference effects and greater activity in the brain networks implicated in selective attention.

\section{Summary of the Goals of the Present Study}

In summary, the goal of the present investigation was to examine the neural systems involved in selective at- tention when distractors were emotional versus nonemotional words. On the basis of the attentional network engaged by the color-word Stroop task (Banich, Milham, Atchley, Cohen, Webb, Wszalek, Kramer, Liang, Barad, et al., 2000; Banich, Milham, Atchley, Cohen, Webb, Wszalek, Kramer, Liang, Wright, et al., 2000; Banich et al., 2001; Milham et al., 2002), our first hypothesis was that overlapping DLPFC regions should be involved in response to the demands to maintain attentional set and to select appropriate task-relevant information, whether or not the salient distractor stimuli are emotional. Our second hypothesis was that emotionally significant distractors should modulate activity in posterior neural regions different from those involved in the color- word Stroop-specifically, engendering more right-hemisphere involvement. In addition, we examined the influence of emotional valence and arousal level on activity in these regions, predicting that, as compared with other types of emotional words, high-arousal negative words would elicit greater activity in the networks involved in maintaining attentional control.

\section{METHOD}

\section{Participants}

The participants were 12 ( 8 male and 4 female) paid volunteers who were recruited from the university community with flyers and e-mails advertising the opportunity to participate in brain-imaging studies. All the participants were right-handed native English speakers who self-reported normal color vision and had no selfreported history of head injury or neurological disorder. Mean age was 25.2 years (range, 20-31).

\section{Experimental Design}

For all the trials, the task was to indicate the color in which a word was presented as quickly as possible while ignoring the word's meaning. Stimulus presentation and collection of response times (RTs) were controlled by MEL V2.0 software. Words were printed in red, yellow, green, or blue, with each color occurring equally often with each word type (see below for word types). Words subtended a visual angle of approximately $7^{\circ}-14^{\circ}$ horizontally, depending on word length. Responses were made by using the first two fingers of each hand on a four-button response pad held above the solar plexus. Each trial lasted $2,000 \mathrm{msec}$, consisting of a $300-\mathrm{msec}$ fixation point followed by a $1,700-\mathrm{msec}$ word presentation, which was immediately followed by the next trial.

Each participant completed three runs lasting approximately $9 \mathrm{~min}$ each. The runs differed from one another only in the types of words presented. One run consisted of alternating epochs of neutral and negative emotion words (NEG run); another consisted of alternating epochs of neutral and positive emotion words (POS run); and the third consisted of alternating epochs of neutral and color words (COL run). The order of runs was counterbalanced across participants.

Prior behavioral studies have demonstrated that emotional words become harder to ignore when they are grouped together into blocks, rather than when they are intermixed with neutral word trials (Holle, Neely, \& Heimberg, 1997; see also Compton et al., 2000; Dalgleish, 1995). Furthermore, real-world emotional information is more likely to occur in a sustained fashion over several minutes, rather than alternating rapidly with information of a different emotional tenor. In addition, multiple pilot studies in our laboratory indicated the presence of an interference effect only for blocked paradigms, and not for event-related designs. A blocked design was therefore selected as most appropriate for examining attentional interference induced by emotional words. 


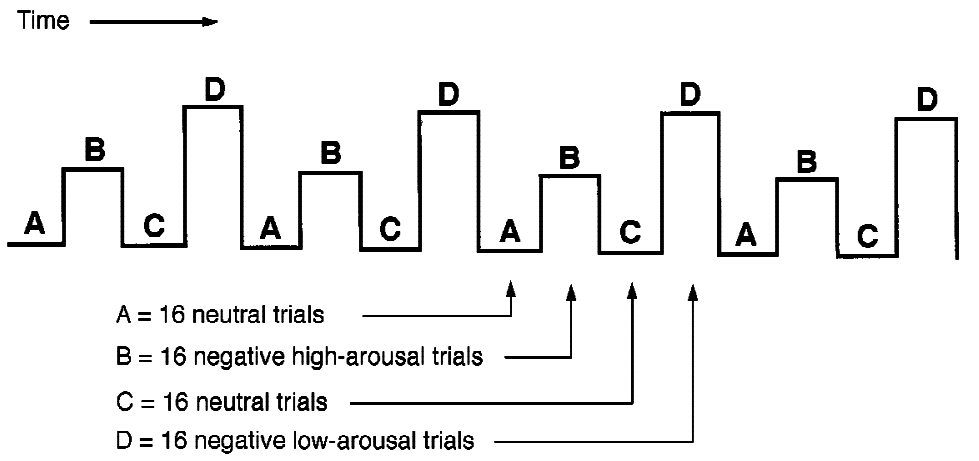

Figure 1. Illustration of the experimental design for the negative word run. Identical designs were used for the positive and the color word runs, with only the word lists differing between runs.

Each of the three runs consisted of 256 trials organized as a series of 16-trial epochs forming a castle design, illustrated in Figure 1. Each epoch included either 16 neutral words or 16 target words (emotion or color). In each consecutive set of four epochs, the first and third epochs (A and C) were composed of neutral word lists, and the second and fourth epochs (B and D) were composed of target word lists. In total, each run consisted of four cycles through this four-epoch sequence (ABCDABCDABCDABCD; see Figure 1). For the NEG run, one target word list included negative high-arousal words, such as panic, and the other target word list included negative low-arousal words, such as sad. For the POS run, one target word list included positive high-arousal words, such as $e x$ cite, and the other included positive low-arousal words, such as peace. The order of target word lists within each run was counterbalanced across participants, so that, for example, within the NEG run, the negative high-arousal word list preceded the negative lowarousal word list for some participants, whereas for other participants the order was reversed. For each run, two different neutral word lists were used for the $\mathrm{A}$ and $\mathrm{C}$ epochs of the sequence, so that neutral words were not repeated any more often than target words.

For the COL run, the two target word lists were constructed to mimic the intensity manipulation present in the high- and lowarousal lists for the NEG and POS runs. This manipulation capitalized on previous findings that Stroop interference is typically greater for conflicting color words that are part of the response set than for color words that are not part of the response set (Klein, 1964; see also Milham et al., 2001, for a similar approach). Here, the response set was the four colors in which the words were printed (red, yellow, green, and blue). Thus, for the COL run, one target word list included incongruent color words that were response-eligible colors, such as red in blue ink, in addition to four words closely related to those colors (see the Appendix). ${ }^{1}$ The second target word list included incongruent color words that were not part of the response set-that is, response-ineligible colors, such as gray in blue ink (when red, yellow, green, and blue were possible responses).

Word stimuli for the four emotion word lists, the two color word lists, and the six neutral word lists are presented in the Appendix. Emotion words were chosen on the basis of available ratings of arousal and valence (Bradley \& Lang, 1998). Each neutral word list was matched as closely as possible to one of the emotion or color word lists on concreteness, imageability, familiarity, and word length, on the basis of published norms (Toglia \& Battig, 1983). Neutral words were chosen to be semantically related within each list, just as the emotion words were semantically related within a list. In addition, 12 undergraduates who were not part of the MRI study completed valence and arousal ratings on all the words used in the study. These participants rated each word on a 7-point pleas- antness scale, in which $1=$ very unpleasant and $7=$ very pleasant , and on a 7-point arousal scale, in which $1=$ not at all arousing and $7=$ highly arousing. Mean valence and arousal ratings for word lists are presented in Table 1.

\section{Equipment and Acquisition Parameters}

Multislice images of the brain were acquired using a $1.5 \mathrm{~T} \mathrm{GE}$ Signa scanner equipped for echo-planar imaging (EPI). For each run, 370 EPI images were acquired $(\mathrm{TR}=1,517 \mathrm{msec}, \mathrm{TE}=$ $40 \mathrm{msec}$, flip angle $=90^{\circ}$ ). Each EPI image included 15 contiguous slices (slice thickness $=7 \mathrm{~mm}$, in-plane resolution $=3.75 \times 3.75 \mathrm{~mm}$ ), oriented parallel to the AC-PC line. Prior to the EPI acquisition, a 26-slice three-dimensional (3-D) sagittal set (T1-weighted 3-D spoiled gradient echo images) and a T1-weighted set corresponding to the 15 EPI slices were acquired for purposes of anatomical landmark selection and registration of the EPI slices. The head coil was fitted with a bite bar to minimize motion, and stimulus images were presented via a goggle system (Magnetic Resonance Technologies). Prior to data analysis, images in each participant's time series were motion corrected, using the AIR V3.0 algorithm.

\section{Analysis of MR Data}

The first six volumes of each run were discarded in order to allow the MR signal to reach steady state. Images in the data series were convolved with a 3-D Gaussian kernel (FWHM $=8 \times 8 \times 8 \mathrm{~mm}$, kernel width $=7 \times 7 \mathrm{~mm})$, temporally denoised using an ID-wavelet transform (visu-shrink, number of levels $=4$ ), and linearly detrended. MEDx V3.4 was used for image processing and statistical analyses.

Data were analyzed via a general linear model approach to identify voxels whose activity covaried in time with aspects of the experimental design (see Milham et al., 2002, for a similar analysis approach). Model fitting was performed separately for the NEG,

Table 1

Mean Valence and Arousal Ratings for Word Lists

\begin{tabular}{lccccc}
\hline & \multicolumn{4}{c}{ Rating } \\
\cline { 2 - 3 } \multicolumn{1}{c}{ Word List } & \multicolumn{2}{c}{ Valence } & & Arousal \\
\cline { 2 - 3 } \cline { 5 - 6 } & $M$ & $S D$ & & $M$ & $S D$ \\
\hline Negative high arousal & 1.65 & 0.74 & & 5.46 & 1.51 \\
Negative low arousal & 1.78 & 0.94 & & 3.48 & 1.91 \\
Positive high arousal & 5.77 & 1.14 & & 5.80 & 1.46 \\
Positive low arousal & 5.97 & 0.82 & & 2.96 & 1.51 \\
Color word eligible & 4.82 & 1.11 & & 3.24 & 1.74 \\
Color word ineligible & 4.09 & 1.24 & & 2.26 & 1.34 \\
Neutral (six lists averaged) & 3.93 & 0.72 & 2.16 & 0.65 \\
\hline
\end{tabular}


POS, and COL runs. For each run, two orthogonal predictors were simultaneously examined. For the NEG and POS runs, the first predictor was constructed to identify areas whose activity was increased by emotion words, regardless of their arousal level, as compared with neutral words (i.e., negative words vs. neutral words for the NEG run, positive words vs. neutral words for the POS run). Thus, for the ABCD design, epochs were weighted $-11-11$, and so on. The second predictor for the POS and NEG runs identified voxels whose activity covaried with the arousal level of emotion words. This predictor contrasted high- versus low-arousal emotional words within a run, ignoring neutral words (weightings for the ABCD design were $010-1$, etc.). These same two predictors were implemented for the COL run, with Predictor 1 indexing incongruence (both types of incongruent trials vs. neutrals) and Predictor 2 indexing response eligibility (response-elig ible vs. response-inelig ible incongruent color words).

For each predictor, the vector of assigned weights corresponding to the experimental design (e.g., $010-1$, etc.) was convolved with a gamma function prior to the regression, to better approximate the hemodynamic function (Aguirre, Zarahn, \& D'Esposito, 1998; Miezin, Maccotta, Ollinger, Petersen, \& Buckner, 2000). In addition, a three-scan lag $(4.55 \mathrm{sec})$ was imposed to account for the lag in the peak hemodynamic response (e.g., Aguirre et al., 1998). For each participant, maps of beta statistics - that is, maps representing the magnitude of activity associated with each predictor, computed for each voxel-were normalized by conversion to $z$ scores and transformed into a common stereotaxic space (Talairach \& Tournoux, 1988). Then, at each voxel, a one-sample $t$ test tested the null hypothesis that the mean across participants was zero. Resulting $t$ statistics were then converted into $z$ scores for ease of interpretation. A voxel was considered activated (i.e., its activity significantly correlated with the predictor) if the $z$ score resulting from the inferential test was $\$ .3$ ( $p<.001$, two-tailed, uncorrected). Clusters of activation were defined by a minimum of nine contiguous voxels significantly activated at $z \geq 3.3$ (see Forman et al., 1995, for a detailed rationale for using cluster thresholds to reduce false positives). Reported clusters are those that fall within the regions of interest outlined in the introduction: the DLPFC, the ACC, the posterior parietal cortex, and posterior processing areas (the occipital and temporal cortex). Motivated by prior research suggesting a link between emotional processing and activation in the amygdala and the OFC, we also interrogated these areas. However, signal strength in these areas was generally lower due to susceptibility artifacts (Ojemann et al., 1997), so conclusions regarding the OFC and the amygdala must be made cautiously.

\section{RESULTS}

\section{Behavioral Data}

Error rates were low overall (less than $3 \%$ ) and did not differ significantly across word types, so analyses fo- cused on RT measures of performance. Table 2 displays the group mean RTs as a function of run and word type. In each of the three runs, RTs from one individual were lost due to technical difficulties. Data were analyzed in a similar fashion to the contrasts developed for the imaging data. The first analysis contrasted emotional words to neutral words within the NEG and POS runs, and the second analy sis contrasted high- and low-arousal emotional words within a run. None of these contrasts reached significance ( $p$ s $>.25$ ), although the means were in the predicted direction. For the COL run, responses were significantly slower to the two types of incongruent color words combined, in contrast to neutral words $[t(10)=3.50, p<.01]$, but response-eligible and response-ineligible incongruent color words did not differ $(p>.50)$. Because responses to emotional stimuli may habituate over time (McKenna \& Sharma, 1995) and because the experimental design required the repetition of words multiple times during the experiment, differences in RTs to emotional versus neutral words may have been present early in the trial run but then may have diminished over time. Therefore, we examined behavioral data from the first cycle of each word type within the run-that is, the first set of 16 trials for each word type. RTs for high-arousal words were slower than those for matched neutral words in the NEG run $[M \mathrm{~s}=748$ vs. $695 \mathrm{msec} ; t(10)=2.55, p<$ $.05]$ but were only marginally slower in the POS run $[M \mathrm{~s}=777$ vs. $714 \mathrm{msec} ; t(10)=1.87, p=.09]$. In contrast, RTs for the first set of low-arousal emotional words did not differ from those for matched neutral words in either the NEG or the POS run $(p s>.60)$. These analyses indicate that the negative high-arousal emotional words produced behavioral interference early in the trial run, although that effect diminished as the participants became more proficient at ignoring the repeated emotional words. The imaging data were not analyzed separately for each cycle, because statistical power would be too limited for meaningful analyses.

Although analyses of the RT data indicate that the emotional Stroop effect was not significant overall in this sample, this null finding is likely due to the small sample size. Results from a recent behavioral study of the emotional Stroop effect (Koven, Heller, Banich, \& Miller, in press) confirmed the small but reliable interference effects from emotional words. The experimental

Table 2

Mean Reaction Time (in Milliseconds) as a Function of Word Type

\begin{tabular}{lcrrrrr}
\hline & \multicolumn{4}{c}{ Word Type } \\
\cline { 2 - 5 } & \multicolumn{2}{c}{ Target } & & $\begin{array}{c}\text { Matched } \\
\text { Neutral }\end{array}$ & \begin{tabular}{c} 
Interference \\
\cline { 2 - 5 }
\end{tabular} \\
\cline { 2 - 5 } & $M$ & $S D$ & & $M$ & $S D$ & \\
(Target - Neutral)
\end{tabular}

Note-Group means are based on individual subject medians. 
design in the behavioral study, which included 138 participants, was closely modeled after the blocked design in the present study, including alternating blocked presentations of emotional and neutral words. In Koven et al.'s behavioral study, interference from negative higharousal words (as compared with neutral words) was $16 \mathrm{msec}$ (Cohen's $d=0.33$ ), and interference from positive high-arousal words (as compared with neutral words) was $10 \mathrm{msec}$ (Cohen's $d=0.24$ ). Both of these interference effects are comparable in magnitude to effects in the present study and were significant at the .001 level in Koven et al.'s study. Thus, the behavioral data from Koven et al. confirm the effectiveness of the present manipulation.

\section{Imaging Data}

Tables 3, 4, and 5 list the clusters of significantly increased activity for color-incongruent versus neutral words, emotion words versus neutral words, and higharousal versus low-arousal emotion words, respectively. The results are presented below in relationship to regions of a priori interest.

DLPFC. As is illustrated in Figure 2, an area of the left DLPFC (BA 9) displayed increased activity across four of the contrasts examined: for incongruent color words versus neutral words (Figure 2A), for response-eligible incongruent color words versus response-ineligible color words (Figure 2B), for negative versus neutral words (Figure 2C), and for high-arousal versus low-arousal negative words (Figure 2D). What is common to all of these contrasts is that they compare a more attentionally demanding condition with a less attentionally demanding condition: Incongruent words introduce conflicting information, as compared with neutral words; responseeligible words conflict at both response and nonresponse levels, whereas response-ineligible words engender conflict only at nonresponse levels; negative words are more likely to capture attention than are neutral words; and high-arousal words are more likely to capture attention than are low-arousal words. The right-DLPFC region also showed increased activity for negative high-arousal versus low-arousal words (Figure 2D). Contrasts involving positive emotion words revealed no significantly increased activity in the DLPFC. Consistent with prior work (Banich, Milham, Atchley, Cohen, Webb, Wszalek, Kramer, Liang, Barad, et al., 2000; Banich, Milham, Atchley, Cohen, Webb, Wszalek, Kramer, Liang, Wright, et al., 2000; Milham et al., 2001), the DLPFC appears to be more engaged in conditions in which it is more difficult to ignore task-irrelevant information.

OFC. As was mentioned previously, interrogation of the medial OFC was limited by susceptibility artifacts, with substantially lower signal strength observed in this region, as compared with the DLPFC. However, in the left lateral OFC (BA 10/11), activity was significantly increased in response to negative words versus neutral words (see Table 4). No clusters of OFC activation in any of the other conditions met the criteria for significance. However, it should be noted that a small area of activation was observed in the left lateral OFC $(x=-36, y=$ $48 ; z=-4$; peak $z$ score $=3.3$, cluster size $<9$ ) in the contrast of incongruent color words versus neutral words, indicating that this region may not only be responsive to emotional stimuli. As will be discussed in more detail in the Discussion section, this region may be especially important for inhibiting salient responses.

ACC/medial frontal lobe. No contrasts produced significant increases in activity within the ACC proper. However, three of the emotion conditions produced increased activity in medial frontal regions just dorsal to the ACC (BA 6). Activity in this region was significantly increased for negative versus neutral words (Table 4), negative high-arousal versus negative low-arousal words (Table 5), and positive high-arousal versus positive low-

Table 3

Regions Activated by the Standard Color-Word Stroop Task

\begin{tabular}{|c|c|c|c|c|c|c|}
\hline \multirow[b]{2}{*}{ Region } & \multirow[b]{2}{*}{ BA } & \multicolumn{3}{|c|}{ Talairach Coordinates } & \multirow{2}{*}{$\begin{array}{c}\text { Peak } \\
z \text { Score }\end{array}$} & \multirow{2}{*}{$\begin{array}{c}\text { Cluster Size } \\
\text { (No. of Voxels) }\end{array}$} \\
\hline & & $x$ & $y$ & $z$ & & \\
\hline \multicolumn{7}{|c|}{ Incongruent Color Versus Neutral Words } \\
\hline \multicolumn{7}{|l|}{ Frontal } \\
\hline Left middle frontal gyrus & 9 & -42 & 36 & 22 & $3.69^{*}$ & 21 \\
\hline Left inferior frontal gyrus & 9 & -48 & 10 & 30 & $3.56^{*}$ & 12 \\
\hline Left middle frontal gyrus & 6 & -24 & 6 & 50 & $3.48 *$ & 11 \\
\hline Parietal & & & & & & \\
\hline Left superior parietal lobule & 7,40 & -30 & -44 & 46 & $4.69 * *$ & 1,052 \\
\hline Occipital & & & & & & \\
\hline Left middle occipital gyrus & 18 & -32 & -78 & 14 & $4.41 * *$ & 53 \\
\hline \multicolumn{7}{|c|}{ Response-Eligible Versus Response-Ineligible Incongruent Color Words } \\
\hline \multicolumn{7}{|c|}{$\mathrm{c}^{2}$} \\
\hline Left subcallosal gyrus & 25 & -2 & 20 & -14 & $4.57 * *$ & 16 \\
\hline Left inferior frontal gyrus & 44 & -46 & 12 & 28 & $3.78 *$ & 29 \\
\hline \multicolumn{7}{|l|}{ Parietal } \\
\hline Left superior parietal lobule & 7 & -32 & -56 & 52 & $4.00^{* *}$ & 75 \\
\hline Right precuneus & 7 & 2 & -56 & 52 & $4.00 * *$ & 17 \\
\hline
\end{tabular}


Table 4

Regions Activated by Emotion Words Versus Neutral Words

\begin{tabular}{|c|c|c|c|c|c|c|}
\hline \multirow[b]{2}{*}{ Region } & \multirow[b]{2}{*}{ BA } & \multicolumn{3}{|c|}{ Talairach Coordinates } & \multirow{2}{*}{$\begin{array}{l}\text { Peak } \\
z \text { Score }\end{array}$} & \multirow{2}{*}{$\begin{array}{c}\text { Cluster Size } \\
\text { (No. of Voxels) }\end{array}$} \\
\hline & & $x$ & $y$ & $z$ & & \\
\hline \multicolumn{7}{|c|}{ Negative Versus Neutral Words } \\
\hline \multicolumn{7}{|l|}{ Frontal } \\
\hline Left middle frontal gyrus & $10 / 11$ & -32 & 44 & -6 & $5.04 * *$ & 49 \\
\hline Left inferior frontal gyrus & 9,45 & -42 & 20 & 18 & $4.61 * *$ & 711 \\
\hline Left middle frontal gyrus & 6 & -26 & 6 & 54 & $4.31 * *$ & 60 \\
\hline Left medial frontal gyrus & 6 & -8 & 10 & 60 & $4.74 * *$ & 233 \\
\hline \multicolumn{7}{|l|}{ Parietal } \\
\hline Left supramarginal gyrus & 40 & -50 & -44 & 30 & $3.80^{*}$ & 33 \\
\hline Right inferior parietal lobule & 40 & 40 & -26 & 44 & $3.45^{*}$ & 16 \\
\hline Left inferior parietal lobule & 40 & -42 & -34 & 46 & $3.74 *$ & 61 \\
\hline \multicolumn{7}{|l|}{ Occipital } \\
\hline Right fusiform gyrus & 19 & 34 & -68 & -6 & $3.83^{*}$ & 49 \\
\hline \multicolumn{7}{|l|}{ Temporal } \\
\hline Left inferior temporal gyrus & 19 & -44 & -60 & -2 & $4.76^{* *}$ & 58 \\
\hline Left superior temporal gyrus & 22 & -54 & -36 & 10 & $4.28 * *$ & 211 \\
\hline Right superior temporal gyrus & 22 & 46 & -22 & 2 & $3.80 *$ & 58 \\
\hline Left superior temporal gyrus & 22 & -46 & -52 & 14 & $3.87 *$ & 22 \\
\hline \multicolumn{7}{|c|}{ Positive Versus Neutral Words } \\
\hline No significant clusters of activatior & & & & & & \\
\hline
\end{tabular}

Note-BA, Brodmann's area. $\quad * p<.001 . \quad * * p<.0001$, two-tailed, uncorrected.

arousal words (Table 5). Increased activity in this region did not reach significance for the color-incongruent words, as compared with neutral words, but there was subthreshold activity (e.g., $x=0, y=17, z=47$; $z$ score $=$ 2.8, $p=.005$, uncorrected).

Parietal cortex. Consistent with prior studies, incongruent color words produced a large area of increased activity in the left superior parietal lobe (BAs 7, 40) when compared with neutral words (see Table 3 and Figure 3). This region also showed increased activity when response-eligible versus response-ineligible color words were compared (Table 3). Activity in this region of the superior parietal was not increased for any of the emotion conditions. Instead, negative emotion words resulted in increased activity in the bilateral inferior parietal lobe, as well as in the left supramarginal gyrus (see Table 4). High-arousal negative words, as compared with low-arousal negative words, also elicited increased activity in the left inferior and the right superior parietal lobes (Table 5). Contrasts involving positive words did

Table 5

Regions Activated by High-Arousal Versus Low-Arousal Emotion Words

\begin{tabular}{|c|c|c|c|c|c|c|}
\hline \multirow[b]{2}{*}{ Region } & \multirow[b]{2}{*}{ BA } & \multicolumn{3}{|c|}{ Talairach Coordinates } & \multirow{2}{*}{$\begin{array}{l}\text { Peak } \\
z \text { Score }\end{array}$} & \multirow{2}{*}{$\begin{array}{c}\text { Cluster Size } \\
\text { (No. of Voxels) }\end{array}$} \\
\hline & & $x$ & $y$ & $z$ & & \\
\hline \multicolumn{7}{|c|}{ Negative High-Arousal Versus Negative Low-Arousal Words } \\
\hline \multicolumn{7}{|l|}{ Frontal } \\
\hline Right middle frontal gyrus & 8 & 40 & 10 & 30 & $3.87 *$ & 121 \\
\hline Right middle frontal gyrus & 6 & 30 & 0 & 44 & $4.04 * *$ & 20 \\
\hline Left middle frontal gyrus & 6,8 & -40 & 12 & 24 & $4.29 * *$ & 329 \\
\hline Right inferior frontal gyrus & 45 & 28 & 26 & 8 & $3.86^{*}$ & 63 \\
\hline Right inferior frontal gyrus & 45 & 42 & 14 & 10 & $3.65^{*}$ & 15 \\
\hline Right medial frontal gyrus & 6 & 2 & 14 & 48 & $3.97 * *$ & 36 \\
\hline \multicolumn{7}{|l|}{ Parietal } \\
\hline Left inferior parietal lobule & 40 & -48 & -38 & 38 & $3.54 *$ & 12 \\
\hline Right superior parietal lobule & 7 & 24 & -58 & 42 & $3.67 *$ & 13 \\
\hline \multicolumn{7}{|l|}{ Occipital } \\
\hline Right lingual gyrus & 18 & 16 & -88 & 0 & $5.02 * *$ & 59 \\
\hline Left cuneus & 17 & -8 & -72 & 12 & $4.68 * *$ & 24 \\
\hline \multicolumn{7}{|l|}{ Temporal } \\
\hline Right middle temporal gyrus & 21 & 54 & -38 & -6 & $3.91 * *$ & 35 \\
\hline \multicolumn{7}{|c|}{ Positive High-Arousal Versus Positive Low-Arousal Words } \\
\hline \multicolumn{7}{|l|}{ Frontal } \\
\hline Left medial frontal gyrus & 6 & -6 & 16 & 60 & $4.14 * *$ & 20 \\
\hline
\end{tabular}

Note-BA, Brodmann's area. $\quad * p<.001 . \quad * * p<.0001$, two-tailed, uncorrected. 
A

C OLOR VS. NEUTRAL

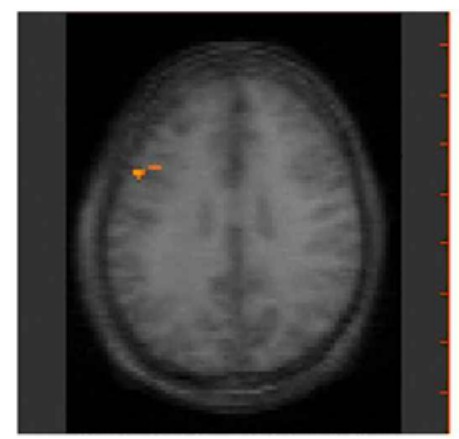

B
C

NEG ATIVE VS. NEUTRAL

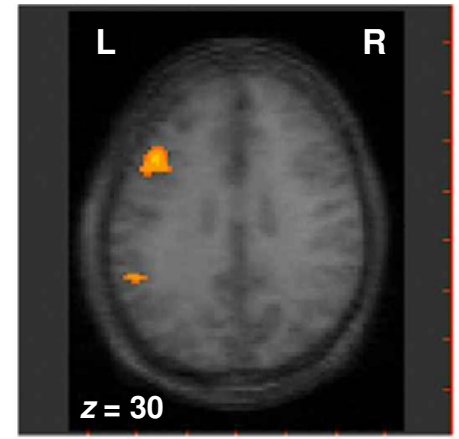

D
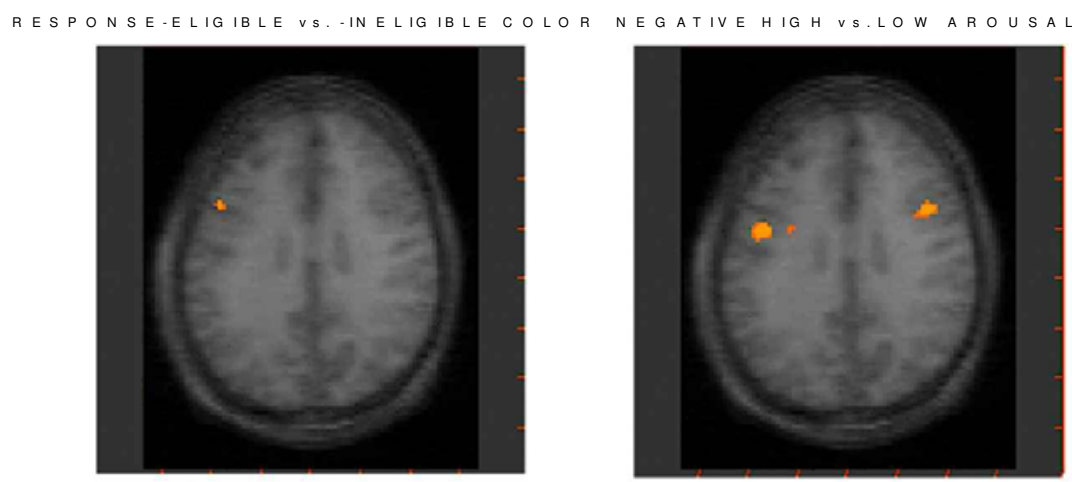

Figure 2. Common area of left dorsolateral prefrontal activity for incongruent color word and negative word contrasts. Highlighted voxels are those whose $z$ scores were 3.3 ( $p<.001$, two-tailed, uncorrected). Increased dorsolateral prefrontal activity was not observed for positive word contrasts (not shown).

not produce any significant effects in the parietal regions.

Occipito-temporal cortex. In contrast to the greater involvement of parietal regions for the color-word Stroop task, the emotion word Stroop task revealed greater involvement of bilateral occipito-temporal regions (see Figure 3). Color-incongruent words produced only a small cluster of increased activity, as compared with neutral words, in the left middle occipital gyrus (BA 18; Table 3). Negative emotion words, as compared with neutral words, produced increased activity in the right fusiform gyrus (BA 19) and in the bilateral superior temporal gyrus (BA 19/22; Table 4). Furthermore, when negative high-arousal words were compared with negative low-arousal words, activity was increased in the cuneus (BA 17), the right lingual gyrus (BA18), and the right middle temporal gyrus (BA 21; Table 5 and Figure 4). Contrasts involving positive words did not produce any significant clusters of activation in occipitotemporal regions. Thus, activity in both parietal and occipito-temporal regions was affected differently by the color-word and the emotional Stroop tasks.

Areas of deactivation. Patterns of deactivation for the contrasts of color-incongruent versus neutral, negative versus neutral, and positive versus neutral words were also examined. Clusters of deactivation were defined by a minimum of nine contiguous voxels with a $z$ score threshold of $\leq 3$.3. The clusters are listed in Table 6 . As can be seen in Table 6 and Figure 5, the three conditions each resulted in significant clusters of deactivation in different parts of the ventral processing stream. For color-incongruent words, activity was significantly decreased, as compared with neutral words, in the bilateral parahippocampal gyrus (BA 30), and the left superior temporal gyrus (BA 22). For negative emotion words, as compared with neutral words, activity in the right amygdaloid region was significantly decreased. Finally, for positive emotion words, as compared with neutral words, activity was decreased throughout large bilateral regions of the occipito-temporal cortex (BAs 17, 18, and 19). Contrasts between negative high-arousal and negative low-arousal words and between positive high-arousal and positive low-arousal words produced no significant clusters of deactivation.

\section{DISCUSSION}

In this experiment, we examined the extent to which neural systems that support selective attention are sensitive to the emotional nature of task-irrelevant informa- 


\section{COLOR vs. NEUTRAL}

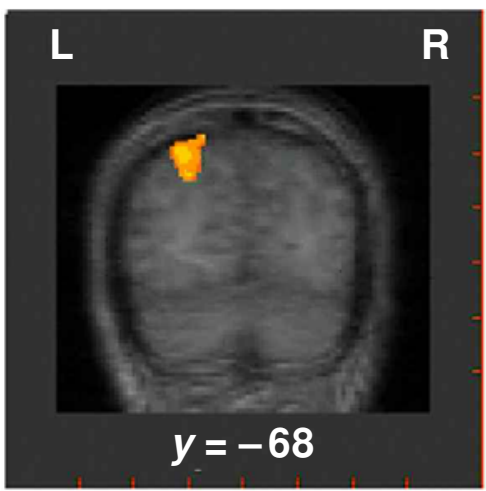

NEGATIVE vs. NEUTRAL

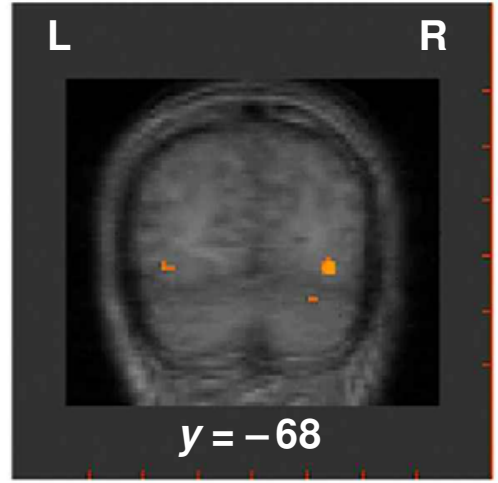

Figure 3. Differences between color-word and negative word tasks in posterior regions whose activity was significantly increased, in comparison with neutral words. Highlighted voxels are those whose $z$ scores were $\mathbb{3} .3(p<.001$, two-tailed, uncorrected). Increased activity was not observed in the positive word task (not shown).

tion. The results revealed that activity increased in overlapping DLPFC regions in response to both incongruent color words and negative emotional words, supporting the notion that these regions are involved in sustaining selective attention in the presence of salient distractors. In posterior regions, the color-word and negative word Stroop tasks differed in areas of both activation and deactivation, reflecting the different regions involved in processing emotional versus nonemotional word meaning. Together, these results imply that attention to emotional information draws on a network of regions acting in concert to maintain attentional set on task-relevant aspects of the stimuli while inhibiting responses to salient but task-irrelevant emotional signals.

\section{Anterior Regions}

The results indicate that the left DLPFC is involved in maintaining attentional set whether or not the challenging task-irrelevant information is emotional. The left DLPFC was more active during the selective attention task when distractors were salient nonemotional words, such as conflicting color words, as well as when they were negative emotional words. Furthermore, the DLPFC was sensitive to the manipulations of intensity within each of these categories, showing greater activity for high-arousal negative words (e.g., danger) than for low-arousal negative words (e.g., $s a d$ ) and also showing greater activity for response-eligible incongruent color words (e.g., blue) than for response-ineligible color words (e.g., gray). These findings imply that a common system of selective attention is engaged when the task requires that one aspect of a stimulus (its color) be attended and another salient aspect (word meaning) be ignored (Banich, Milham, Atchley, Cohen, Webb, Wszalek, Kramer, Liang, Barad, et al., 2000; Banich, Milham, Atchley, Cohen, Webb, Wszalek, Kramer, Liang, Wright, et al., 2000). Maintaining attention on the color dimension of the stimulus was more challenging for both incongruent color words and high-arousal negative words than for neutral or low-arousal words. This is supported by the fact that RTs were significantly slower to incongruent trials throughout the run and to high-arousal negative words early in the run, as compared with matched neutral words. In contrast, DLPFC activity was not increased for positive emotional words, which produced no significant behavioral interference either throughout the run or at the beginning of the run. Thus, activity in the DLPFC was increased only when the challenge to remain focused on the color dimension was also increased.

Data from a separate control condition for the present study reinforced the conclusion that DLPFC activity is modulated by attentional demands in this paradigm,

\section{NEGATIVE HIGH AROUSAL vs. NEGATIVE LOW AROUSAL}

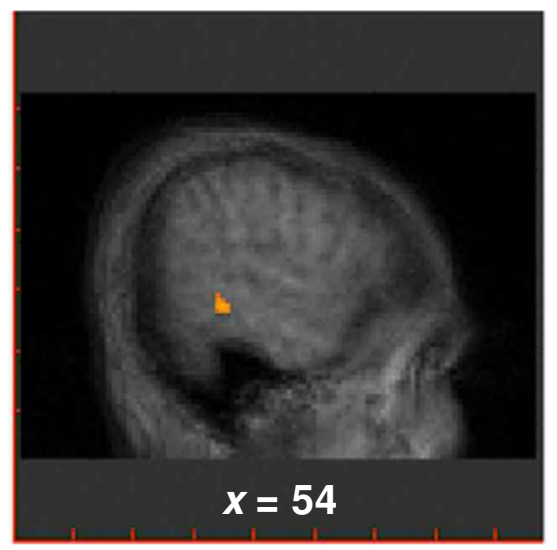

Figure 4. Greater activity in the right temporal lobe for negative high-arousal words than for negative low-arousal words. Highlighted voxels are those whose $z$ scores were $\ .3(p<.001$, two-tailed, uncorrected). Activity in this region was not significantly increased for color word or positive word conditions (not shown). 
Table 6

Regions of Significant Deactivation

\begin{tabular}{|c|c|c|c|c|c|c|}
\hline \multirow[b]{2}{*}{ Region } & \multirow[b]{2}{*}{ BA } & \multicolumn{3}{|c|}{ Talairach Coordinates } & \multirow{2}{*}{$\begin{array}{c}\text { Peak } \\
z \text { Score } \\
\end{array}$} & \multirow{2}{*}{$\begin{array}{c}\text { Cluster Size } \\
\text { (No. of Voxels) }\end{array}$} \\
\hline & & $x$ & $y$ & $z$ & & \\
\hline \multicolumn{7}{|c|}{ Color-Incongruent Versus Neutral Words } \\
\hline \multicolumn{7}{|l|}{ Parietal } \\
\hline Left inferior parietal lobule & 40 & -60 & -34 & 26 & $4.16 * *$ & 102 \\
\hline Right paracentral lobule & $5 / 7$ & 8 & -36 & 50 & $3.96 * *$ & 50 \\
\hline \multicolumn{7}{|l|}{ Temporal } \\
\hline Right parahippocampal gyrus & 30 & 28 & -36 & -4 & $3.95 * *$ & 21 \\
\hline Left parahippocampal gyrus & 30 & -28 & -46 & 2 & $3.96 * *$ & 59 \\
\hline Left superior temporal gyrus & 22 & -50 & -8 & 0 & $3.87 *$ & 89 \\
\hline Left insula & 6 & 44 & -8 & 14 & $3.53 *$ & 14 \\
\hline \multicolumn{7}{|c|}{ Negative Versus Neutral Words } \\
\hline Right peri-amygdaloid region & & 20 & 2 & -24 & $3.62 *$ & 9 \\
\hline \multicolumn{7}{|c|}{ Positive Versus Neutral Words } \\
\hline \multicolumn{7}{|l|}{ Frontal } \\
\hline Right middle frontal gyrus & 10 & 30 & 56 & -8 & $4.20 * *$ & 17 \\
\hline Right middle frontal gyrus & 9 & 26 & 34 & 36 & $3.58^{*}$ & 13 \\
\hline Left middle frontal gyrus & 9 & -28 & 34 & 44 & $3.96 * *$ & 110 \\
\hline \multicolumn{7}{|l|}{ Parietal } \\
\hline Right paracentral lobule & $5 / 7$ & 2 & -38 & 50 & $4.09 * *$ & 94 \\
\hline \multicolumn{7}{|l|}{ Occipital } \\
\hline Right lingual gyrus & 19 & 22 & -48 & 0 & $4.80 * *$ & 357 \\
\hline Right lingual gyrus & 18 & 12 & -80 & -6 & $4.49 * *$ & 290 \\
\hline Left lingual gyrus & 19 & -8 & -36 & 2 & $4.76^{* *}$ & 799 \\
\hline Left cuneus & 17 & -4 & -80 & 12 & $4.20 * *$ & 189 \\
\hline
\end{tabular}

Note-BA, Brodmann's area. $\quad * p<.001 . \quad * * p<.0001$, two-tailed, uncorrected.

specifically by the demand to ignore salient information, such as emotional or color-incongruent words. In that experiment, we asked participants to make word-nonword judgments about the same stimuli as those that we presented in the present study. The lexical decision did not require selective attention, because it did not require the participants to ignore the salient word meaning information. Under these circumstances, activity in the DLPFC was not modulated by word type, as it was in the emotional Stroop paradigm. These data further support the interpretation that the modulation of DLPFC activity in the present study is due to the increased attentional demands imposed by attempting to ignore salient words.
Activity in the left lateral OFC was increased for negative emotion words, as compared with neutral words, corresponding with neuropsychological, anatomical, and other neuroimaging findings indicating that OFC regions play an important role in emotional processing (e.g., Barbas, 2000; Critchley et al., 2000; Damasio, 1995; Elliott, Frith, \& Dolan, 1997). Recently, researchers have identified functional distinctions between lateral and medial OFC regions. For example, Elliott, Dolan, and Frith (2000) argued that the medial OFC is more involved in maintaining reward incentives in mind, whereas the lateral OFC is more involved in inhibiting prepotent responses (see also Nobre, Coull, Frith, \& Mesulam, 1999;
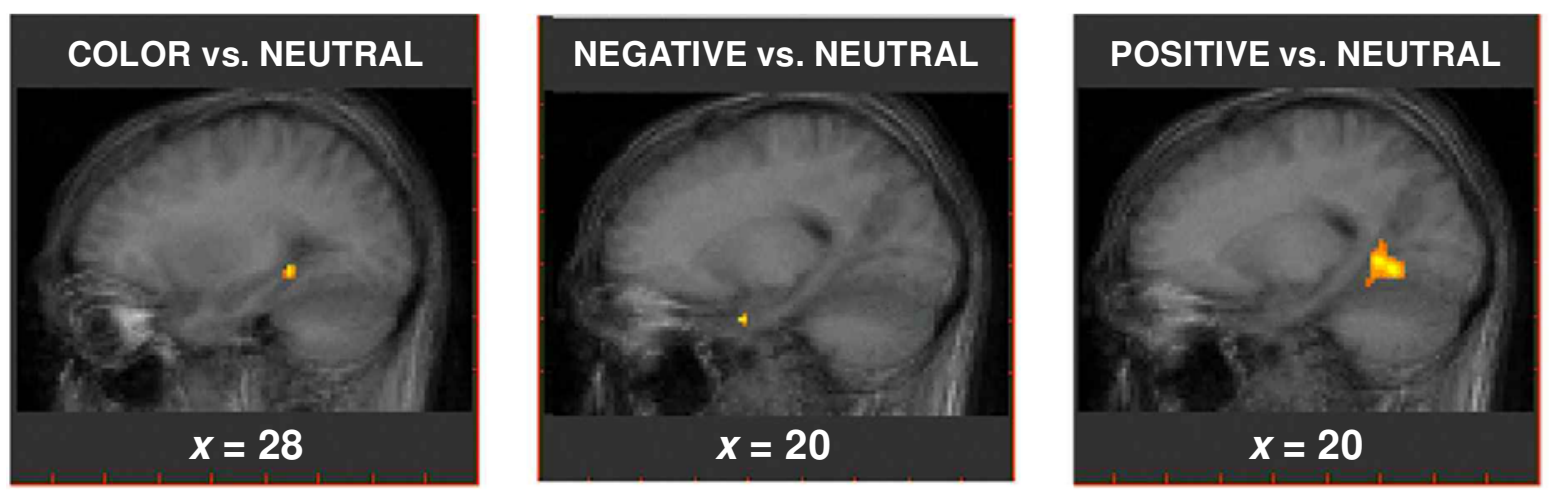

Figure 5. A reas of decreased activity in the ventral processing stream when the participants ignored color-incongruent words, negative words, and positive words, as compared with neutral words. Highlighted voxels are those whose $z$ scores were $\leq \mathbf{3 . 3}$ $(p<.001$, two-tailed, uncorrected $)$. 
O'Doherty, Kringelbach, Rolls, Hornak, \& Andrews, 2001). The emotional Stroop conditions in the present study required inhibiting emotional information, and OFC activation was localized in the lateral region, consistent with the proposal that this region is involved in inhibition. However, because we noted subthreshold activation in this region for the color-word Stroop as well, the present data do not permit a strong attribution of an emotional versus a cognitive function to this region. Rather, the OFC may be involved in inhibition of responses regardless of whether those responses are emotional or nonemotional.

The present data cannot directly address earlier proposals that the ACC is divided into emotional versus cognitive sectors (Bush et al., 2000; Drevets \& Raichle, 1998; Whalen et al., 1998), because activity in the ACC proper was not significantly influenced by any of the conditions in the present study. Although Stroop tasks often modulate activity in the ACC (e.g., Banich et al., 2001; Carter et al., 1995; Pardo et al., 1990), the present experimental design was longer and involved more conditions than did previous studies, perhaps introducing practice effects or alternative strategies that lessened the involvement of the ACC (e.g., Bush et al., 1998; see also Taylor, Kornblum, Lauber, Minoshima, \& Koeppe, 1997). A recent study performed in our laboratory showed a significant reduction in ACC activity over the first, middle, and last thirds of trials in a Stroop task in which interference had been engendered through training. In this task, individuals were taught to associate color names with previously unfamiliar shapes. For the first third of the run, ACC activity was greater for items shown in colors incongruent with their newly learned names (e.g., the shape named blue shown in yellow) than for items shown in white, a color not associated with any shape. By the last third of the run, there was evidence of deactivation of the ACC (Milham, Banich, Claus, \& Cohen, 2003). These recent data support the notion that ACC activation may be especially susceptible to practice effects (e.g., Bush et al., 1998). In addition, the present study involved blocks of $100 \%$ incongruent trials, whereas prior studies (e.g., Banich, Milham, Atchley, Cohen, Webb, Wszalek, Kramer, Liang, Wright, et al., 2000; Banich et al., 2001) presented incongruent trials mixed with neutral trials. Because incongruent Stroop trials are more difficult when their frequency is lower (MacLeod, 1991), incongruent trials could, therefore, elicit greater ACC activity in intermixed conditions than in the $100 \%$ blocks used in the present study. Supporting this idea, another recent study in our laboratory demonstrated greater activity of the ACC for trials that were lower rather than higher in frequency of occurrence (Milham, Banich, \& Barad, in press).

Nevertheless, three of the emotion contrasts highlighted activity in the supplementary motor area dorsal to the ACC, a region that also showed subthreshold activity in the color-word Stroop in the present study and in our prior studies. These findings are consistent with current theorizing that dorsal medial prefrontal regions may be involved in selecting a behavioral response, a function that may be taxed by both color-conflicting words and emotionally salient words (Braver, Barch, Gray, Molfese, \& Snyder, 2001; Milham et al., 2001). In studies of emotion, the medial frontal cortex has been implicated in attending to internal emotional states (Lane, Fink, Chau, \& Dolan, 1997), generating emotional responses to pictures (Teasdale et al., 1999), and generating emotional plans (Partiot, Grafman, Sadato, Wachs, \& Hallett, 1995). These apparently diverse functions have in common the selection of behavioral responses in situations in which multiple competing actions are possible. Because emotions are often conceived of as facilitating actions (e.g., Lang et al., 1990), it is logical that regions of the brain involved in action selection would be engaged when an individual must select between emotion-based action preparation (i.e., behavioral response to danger signals) and taskrelevant responses (i.e., response to an ink color).

\section{Posterior Regions}

Posterior brain regions were differently affected by the emotional versus color-word Stroop tasks, as reflected both in patterns of increased activity and in patterns of decreased activity. Whereas the color-word task increased activity in a wide swath of the left superior parietal cortex, replicating prior findings (e.g., Banich et al., 2001), activity in this region was not modulated by any of the emotion word tasks. Instead, negative emotion words produced greater bilateral activity in occipitotemporal regions, extending prior reports of increased activity in visual-processing areas when participants view emotional pictures (Lane et al., 1999; Lane, Reiman, et al., 1997; Lang et al., 1998). The greater involvement of right occipito-temporal regions, especially in response to the high-arousal versus the low-arousal negative words, is consistent with the notion that the right hemisphere serves an emotional surveillance function that is especially sensitive to signals of threat (Nitschke et al., 2000). Since a similar pattern of right posterior activity was not observed for positive high-arousal words, it appears that it is the specific combination of negative valence and high arousal, and not high arousal alone, that facilitates activity in this region. This increased right posterior activity provides a mechanism for enhanced right-hemisphere performance in response to threatening information, as has been reported in previous divided visual field studies (e.g., Compton et al., 2000; Van Strien \& Heijt, 1995; Van Strien \& Morpurgo, 1992). Furthermore, the fact that right frontal regions were also differentially activated by negative high arousal versus negative low-arousal words suggests that the right hemisphere's emotional surveillance system may be distributed throughout both anterior and posterior regions. Alternatively, the right frontal finding can be interpreted as supporting the proposal that activity in that region is associated with unpleasant emotion (e.g., Davidson, 1995; Heller, 1993).

Finally, results revealed that the color-word and emotional Stroop tasks differed in posterior regions of deac- 
tivation. The difference between tasks in the areas of decreased activity fits with the notion that although both color-word and emotional Stroop tasks require an attentional set to be established, the tasks differ in the nature of the representations that need to be ignored or suppressed. That is, in the color-word Stroop, participants must inhibit representations of the meaning of color-word information, whereas in the emotional Stroop, participants must inhibit representations of emotional meaning.

For the color-word task, the bilateral deactivation in the parahippocampal regions, which we have also observed in prior color-word Stroop studies (Banich \& Milham, unpublished observations), may be linked to the binding function served by the hippocampal system. Prior work indicates that this system is crucial in binding together or associating information in distinct cortical processing streams (Cohen \& Eichenbaum, 1993; O'Reilly \& Rudy, 2000). We propose that for incongruent trials in the color-word Stroop task, binding together of the ink color and the conflicting word meaning is especially detrimental to performance and, therefore, must be inhibited, resulting in deactivation of the hippocampal system.

In contrast, the finding of reduced activity in the periamygdaloid region in response to negative words, as compared with neutral words, suggests that ignoring irrelevant negative information involves inhibiting the amygdala or associated regions. This finding at first appears inconsistent with a prior report of increased amygdala activation during an emotional Stroop task (Isenberg et al., 1999). However, the two studies differed in methodological details that may account for the apparently discrepant findings. Isenberg et al.'s study involved 80 different negative words, whereas the present study involved a set of 16 negative words that were each repeated four times. The number of unique emotion words in the present study was constrained by the goal of making the emotional Stroop directly comparable with the color-word Stroop task, which is limited to a small set of color words. As a result, the repetition of negative emotion words throughout the series of trials may have made it easier for the participants to inhibit the amygdala's response to those words, as compared with Isenberg et al.'s study, in which each item was novel. This explanation is particularly likely given evidence that the amygdala habituates rapidly (e.g., Breiter et al., 1996). The present results indicate that deactivation of the amygdala in the face of irrelevant threats may be a crucial mechanism of emotional regulation, consistent with recent findings from other paradigms (Beauregard, Levesque, \& Bourouin, 2001; O'Reardon et al., 2003; Schaefer et al., 2002).

\section{Role of Emotional Valence and Arousal}

Consistent with the notion that negative emotional information is more salient than positive emotional information, reliable increases in activity in attentional networks were observed when the participants had to ignore negative emotional information, but not when the participants had to ignore positive information, even when the mean arousal levels of positive and negative words were equated on the basis of pilot ratings. In fact, for positive emotional words, activity actually decreased in the DLPFC and the ventral visual processing stream, as compared with neutral words. Within the category of negative words, high-arousal words (e.g., danger) produced greater activity than did low-arousal words (e.g., $s a d$ ) in the DLPFC and in occipito-temporal regions.

These findings support the notion that signals of threat are especially attentionally demanding, even in comparison with other emotional stimuli. Indeed, negatively and positively valenced cues may differ in their functional significance for the organism. Threats of danger are likely to call for immediate redirection of attention (e.g., Öhman, 1997), whereas positive emotional cues may elicit a broaden-and-build strategy that does not involve a selective focusing of attention (e.g., Fredrickson, 1998). The environmental context of the scanning session, which was novel and strange for most participants, may also have increased the emotional relevance of words such as danger and fear more than that of positive words such as romantic or comfort, potentially magnifying the effects of emotional valence and arousal level on the results.

\section{Limitations}

Although the predictions from our theoretical framework yielded many significant findings, the results have some limitations. Most notably, the emotional Stroop task did not produce the same degree of behavioral interference as did the color-word Stroop, limiting the comparison between the two tasks (see Whalen et al., 1998, for similar results). However, the absence of a large behavioral difference between negative and neutral words (except for early in the trial run) can be interpreted in a positive light, particularly when considered together with the substantial neural activity differences between negative and neutral words - namely, that the neural regions whose activity is increased during negative versus neutral word conditions are the regions that are working to maintain effective cognitive performance in the face of emotionally salient distractors. Thus, the brain-imaging data can provide a window onto internal mental processes that are not reflected in RT.

To extend these findings, future studies should examine clinical samples, such as individuals with generalized anxiety disorder or posttraumatic stress disorder, who are likely to exhibit much larger behavioral interference on the emotional Stroop task than did the nonclinical sample in the present study (Williams et al., 1996). Such comparisons can contrast the brain areas involved in effective coping with emotional distractors, as in the present study, to brain areas in anxious individuals who are not effectively coping with such distractors.

\section{Summary}

The present data support the notion that the degree to which cognition and emotion involve similar or different 
brain regions depends on the degree to which they involve similar or different processing components. Tasks classified as cognitive and emotional may draw upon overlapping brain regions when they share common processing components, such as the need to maintain attention on one aspect of a stimulus while ignoring another salient dimension. In the present study, ignoring distractors in a Stroop paradigm engaged anterior attentional regions, such as the DLPFC and the medial prefrontal cortex, regardless of whether the task involved emotional or nonemotional distractors. On the other hand, distinct processing components in each task appear to recruit activity in distinct brain regions. The emotional Stroop task engaged right posterior regions involved in threat perception that were not recruited by the color-word Stroop task. An emphasis on the component processes underlying task performance may thus help to clarify the neuroanatomical circuits involved in cognitive and emotional processing and their relationship to each other (e.g., whether they are reciprocal or integral). An intriguing avenue for future research will be to examine how activity within these circuits is altered in individuals who have difficulty in emotional regulation.

\section{REFERENCES}

Aguirre, G. K., Zarahn, E., \& D'Esposito, M. (1998). The variability of human BOLD hemodynamic response. Neurolmage, 8, 360-369. Asbjornsen, A., Hugdahl, K., \& Bryden, M. P. (1992). Manipulations of subjects' level of arousal in dichotic listening. Brain \& Cognition, 19, 183-194.

Banich, M. T., Milham, M. P., Atchley, R., Cohen, N. J., Webb, A., Wszalek, T., Kramer, A. F., Liang, Z-P., Barad, V., Gullett, D., Shah, C., \& Brown, C. (2000). Prefrontal regions play a predominant role in imposing an attentional "set": Evidence from fMRI. Cognitive Brain Research, 10, 1-9.

Banich, M. T., Milham, M. P., Atchley, R., Cohen, N. J., Webb, A., Wszalek, T., Kramer, A. F., Liang, Z-P., Wright, A., Shenker, J., \& Magin, R. (2000). fMRI studies of Stroop tasks reveal unique roles of anterior and posterior brain systems in attentional selection. Journal of Cognitive Neuroscience, 12, 988-1000.

Banich, M. T., Milham, M. P., Jacobson, B. L., Webb, A., Wszalek, T., Cohen, N. J., \& Kramer, A. F. (2001). Attentional selection and the processing of task-irrelevant information: Insights from fMRI examinations of the Stroop task. In C. Casanova \& M. Ptito (Eds.), Vision: From neuroses to cognition (Progress in Brain Research, Vol. 134, pp. 459-470). Amsterdam: Elsevier.

BARBAS, H. (2000). Connections underlying the synthesis of cognition, memory, and emotion in primate prefrontal cortices. Brain Research Bulletin, 52, 319-330.

BEAR, D. M. (1983). Hemispheric specialization and the neurology of emotion. Archives of Neurology, 40, 195-202.

Beauregard, M., Levesque, J., \& Bourouin, P. (2001). Neural correlates of conscious self-regulation of emotion. Journal of Neuroscience, 21, RC165 (1-6).

Bench, C. J., Frith, C. D., Grasby, P. M., Friston, K. J., Paulesu, E., Frackowiak, R. S. J., \& Dolan, R. J. (1993). Investigations of the functional anatomy of attention using the Stroop test. Neuropsychologia, 31, 907-922.

Bradley, M. M., \& LANG, P. J. (1998). Affective norms for English words (ANEW). Gainesville, FL: University of Florida, NIMH Center for the Study of Emotion and Attention.

Braver, T. S., Barch, D. M., Gray, J. R., Molfese, D. L., \& Snyder, A. (2001). Anterior cingulate cortex and response conflict: Effects of frequency, inhibition, and errors. Cerebral Cortex, 11, 825-836.

Breiter, H. C., Etcoff, N. L., Whalen, P. J., Kennedy, W. A., Rauch, S. L., Buckner, R. L., Strauss, M. M., Hyman, S. E., \&
Rosen, B. R. (1996). Response and habituation of the human amygdala during visual processing of facial expression. Neuron, 17, 875-887.

Bush, G., LuU, P., \& Posner, M. I. (2000). Cognitive and emotional influences in anterior cingulate cortex. Trends in Cognitive Sciences, $\mathbf{4}$, 215-222.

Bush, G., Whalen, P. J., Rosen, B. R., Jenike, M. A., McInerney, S. C., \& RAUCH, S. L. (1998). The counting Stroop: An interference task specialized for functional neuroimaging-Validation study with functional MRI. Human Brain Mapping, 6, 270-282.

Carter, C. S., Mintun, M., \& Cohen, J. D. (1995). Interference and facilitation effects during selective attention: An H-2-15-O PET study of Stroop task performance. NeuroImage, 2, 264-272.

Cohen, N. J., \& Eichenbaum, H. (1993). Memory, amnesia, and the hippocampal system. Cambridge, MA: MIT Press.

Compton, R. J., Heller, W., Banich, M. T., Palmieri, P. A., \& Miller, G. A. (2000). Responding to threat: Hemispheric asymmetry and interhemispheric division of input. Neuropsychology, 14, 254-264.

Critchley, H. D., Elliott, R., Mathias, C. J., \& Dolan, R. J. (2000). Neural activity relating to generation and representation of galvanic skin conductance responses: A functional magnetic resonance imaging study. Journal of Neuroscience, 20, 3033-3040.

DAlgleish, T. (1995). Performance on the emotional Stroop task in groups of anxious, expert, and control subjects: A comparison of computer and card presentation formats. Cognition \& Emotion, 9 , 341-362.

Dalgleish, T., \& Watts, F. N. (1990). Biases of attention and memory in disorders of anxiety and depression. Clinical Psychology Review, 10, 589-604.

DAmAsio, A. (1995). On some functions of the human prefrontal cortex. In J. Grafman \& K. J. Holyoak (Eds.), Structure and functions of the human prefrontal cortex (Annals of the New York Academy of Sciences, Vol. 769, pp. 241-251). New York: New York Academy of Sciences.

DAvidson, R. J. (1995). Cerebral asymmetry, emotion, and affective style. In R. J. Davidson \& K. Hugdahl (Eds.), Brain asymmetry (pp. 361-387). Cambridge, MA: MIT Press.

Devinsky, O., Morrell, M. J., \& Vogt, B. A. (1995). Contributions of anterior cingulate cortex to behaviour. Brain, 118, 279-306.

Drevets, W. C., \& Raichle, M. E. (1998). Reciprocal suppression of regional cerebral blood flow during emotional versus higher cognitive processes: Implications for interaction between emotion and cognition. Cognition \& Emotion, 12, 353-385.

Elliott, R, Dolan, R. J., \& Frith, C. D. (2000). Dissociable functions in the medial and lateral orbitofrontal cortex: Evidence from human neuroimaging studies. Cerebral Cortex, 10, 308-317.

Elliott, R., Frith, C. D., \& Dolan, R. J. (1997). Differential neural response to positive and negative feedback in planning and guessing tasks. Neuropsychologia, 35, 1395-1404.

Forman, S. D., Cohen, J. D., Fitzgerald, M., Eddy, W. F., Mintun, M. A., \& NolL, D. C. (1995). Improved assessment of significant activation in functional magnetic resonance imaging (fMRI): Use of a cluster-size threshold. Magnetic Resonance in Medicine, 33, 636-647.

Fredrickson, B. L. (1998). What good are positive emotions? Review of General Psychology, 2, 300-319.

George, M. S., Ketter, T. A., Parekh, P. I., Rosinsky, N., Ring, H. A. Casey, B. J., Trimble, M. R, Horwitz, B., Herscovitch, P., \& Post, R. M. (1994). Regional brain activity when selecting a response despite interference: $\mathrm{An} \mathrm{H}_{2}{ }^{15} \mathrm{O}$ PET study of the Stroop and an emotional Stroop. Human Brain Mapping, 1, 194-209.

George, M. S., Ketter, T. A., Parekh, P. I., Rosinsky, N., Ring, H. A., Pazzaglia, P. J., Marangell,L. B., Callahan, A. M., \& Post, R. M. (1997). Blunted left cingulate activation in mood disorder subjects during a response interference task (the Stroop). Journal of Neuropsychiatry \& Clinical Neurosciences, 9, 55-63.

Gray, J. S., Braver, T. S., \& Raichle, M. E. (2002). Integration of emotion and cognition in the lateral prefrontal cortex. Proceedings of the National Academy of Sciences, 99, 4115-4120.

Gruzelier, J., \& Phelan, M. (1991). Stress induced reversal of a lexical divided visual-field asymmetry accompanied by retarded electrodermal habituation. International Journal of Psychophysiology, 11, 269-276. 
HELLER, W. (1993). Neuropsychological mechanism of individual differences in emotion, personality, and arousal. Neuropsychology, 7, 476-489.

Heller, W., \& NitschKe, J. B. (1997). Regional brain activity in emotion: A framework for understanding cognition in depression. Cognition \& Emotion, 11, 637-661.

Heller, W., Nitschke, J. B., \& Lindsay, D. L. (1997). Neuropsychological correlates of arousal in self-reported emotion. Cognition \& Emotion, 11, 383-402.

Holle, C., Neely, J., \& Heimberg, R. (1997). The effects of blocked versus random presentation and semantic relatedness of stimulus words on response to a modified Stroop task among social phobics. Cognitive Therapy \& Research, 21, 681-697.

Isenberg, N., Silbersweig, D., Engelien, A., Emmerich, S., Malavade, K., Beattie, B., Leon, A. C., \& Stern, E. (1999). Linguistic threat activates the human amygdala. Proceedings of the $\mathrm{Na}$ tional Academy of Sciences, 96, 10456-10459.

KLEIN, G. S. (1964). Semantic power measured through the interference of words with color-naming. American Journal of Psychology, 77, 576-588.

Koven, N. S., Heller, W., Banich, M. T., \& Miller, G. A. (in press). Relationships of distinct affective dimensions to performance on an emotional Stroop task. Cognitive Therapy \& Research.

Lane, R. D., Chua, P. M. L., \& Dolan, R. J. (1999). Common effects of emotional valence, arousal and attention on neural activation during visual processing of pictures. Neuropsychologia, 37, 989-997.

Lane, R. D., Fink, G. R., Chua, P. M.-L., \& Dolan, R. J. (1997). Neural activation during selective attention to subjective emotional responses. NeuroReport, 8, 3969-3972.

Lane, R. D., Reiman, E. M., Bradley, M. M., Lang, P. J., Ahern, G. L., Davidson, R. J., \& Schwartz, G. E. (1997). Neuroanatomical correlates of pleasant and unpleasant emotion. Neuropsychologia, 35, 1437-1444.

Lang, P. J., Bradley, M. M., \& Cuthbert, B. N. (1990). Emotion, attention, and the startle reflex. Psychological Review, 97, 377-395.

Lang, P. J., Bradley, M. M., Fitzsimmons, J. R., Cuthbert, B. N., ScotT, J. D., Moulder, B., \& NANGiA, V. (1998). Emotional arousal and activation of the visual cortex: An fMRI analysis. Psychophysiology, 35, 199-210.

Lang, P. J., Greenwald, M. K., Bradley, M. M., \& Hamm, A. (1993). Looking at pictures: Affective, facial, visceral, and behavioral reactions. Psychophysiology, 30, 261-273.

Larsen, R. J., \& Diener, E. (1992). Promises and problems with the circumplex model of emotion. In M. S. Clark (Ed.), Review of personality and social psychology: Emotion (Vol. 13, pp. 25-59). Newbury Park, CA: Sage.

MACLEOD, C. M. (1991). Half a century of research on the Stroop effect: An integrative review. Psychological Bulletin, 109, 163-203.

MACLEOD, C. M. (1992). The Stroop task: The "gold standard" of attentional measures. Journal of Experimental Psychology: General, 121, 12-14.

Mathews, A., \& MacLeod, C. (1985). Selective processing of threat cues in anxiety states. Behavioural Research \& Therapy, 23, 563-569.

McKenna, F. P., \& Sharma, D. (1995). Intrusive cognitions: An investigation of the emotional Stroop task. Journal of Experimental Psychology: Learning, Memory, \& Cognition, 21, 1595-1607.

Miezin, F. M., Maccotta, L., Ollinger,J. M., Petersen, S. E., \& BucKNER, R. L. (2000). Characterizing the hemodynamic response: Effects of presentation rate, sampling procedure, and the possibility of ordering brain activity based on relative timing. NeuroImage, 11, 735-759.

Milham, M. P., BANich, M. T., \& BARAD, V. (in press). Competition for priority in processing increases prefrontal cortex's involvement in top-down control: An event-related fMRI study of the Stroop task. Cognitive Brain Research.

Milham M. P., Banich, M. T., Claus, E., \& Cohen, N. J. (2003). Practice-related effects demonstrate complementary roles of anterior cingulate and prefrontal cortices in attentional control. NeuroImage, 18, 483-493.

Milham, M. P., Banich, M. T., Webb, A., Barad, V., Cohen, N. J., Wszalek, T., \& Kramer, A. F. (2001). The relative involvement of anterior cingulate and prefrontal cortex in attentional control depends on nature of conflict. Cognitive Brain Research, 12, 467-473.
Milham, M. P., Erickson, K. I., Banich, M. T., Kramer, A. F., Webb, A., WszaleK, T., \& COHEN, N. J. (2002). Attentional control in the aging brain: Insights from an fMRI study of the Stroop task. Brain \& Cognition, 49, 277-296.

Miller, G. A. (1996). How we think about cognition, emotion, and biology in psychopathology. Psychophysiology, 33, 615-628.

Mogg, K., Mathews, A., \& Weinman, J. (1989). Selective processing of threat cues in anxiety states: A replication. Behaviour Research \& Therapy, 27, 317-323.

Nitschke, J. B., Heller, W., \& Miller, G. A. (2000). Anxiety, stress, and cortical brain function. In J. C. Borod (Ed.), The neuropsychology of emotion (pp. 298-319). New York: Oxford University Press.

Nitschke, J. B., Heller, W., Palmieri, P. A., \& Miller, G. A. (1999). Contrasting patterns of brain activity in anxious apprehension and anxious arousal. Psychophysiology, 36, 628-637.

Nobre, A. C., Coull, J. T., Frith, C. D., \& Mesulam, M. M. (1999). Orbitofrontal cortex is activated during breaches of expectation in tasks of visual attention. Nature Neuroscience, 2, 11-12.

O’Doherty, J., Kringelbach, M. L., Rolls, E. T., Hornak, J., \& ANDREWS, C. (2001). Abstract reward and punishment representations in the human orbitofrontal cortex. Nature Neuroscience, 4, 95-102.

ÖHman, A. (1997). As fast as the blink of an eye: Evolutionary preparedness for the preattentive processing of threat. In P. J. Lang, R. F. Simons, \& M. T. Balaban (Eds.), Attention and orienting: Sensory and motivational processes (pp. 165-184). Mahwah, NJ: Erlbaum.

Ojemann, J. G., Akbudak, E., Snyder, A. Z., McKinstry, R. C., Raichle, M. E., \& Conturo, T. E. (1997). Anatomic localization and quantitative analysis of gradient refocused echo-planar fMRI susceptibility artifacts. NeuroImage, 6, 156-167.

O'Reardon, J. P., Brotman, M. A., DeRubeis, R. J., Wang, J. J., Detre, J. A., Egeth, M. J., Cornew, L. A., \& Farah, M. J. (2003). Prefrontal-amygdala interaction and mood regulation: A perfusion f MRI study. Brain \& Cognition, 51, 184-186.

O'ReIlly, R. C., \& Rudy, J. W. (2000). Computational principles of learning in the neocortex and hippocampus. Hippocampus, 10, 389397.

Pardo, J. V., Pardo, P. J., Janer, K. W., \& Raichle, M. E. (1990). The anterior cingulate cortex mediates processing selection in the Stroop attentional conflict paradigm. Proceedings of the National Academy of Sciences, 87, 256-259.

Partiot, A., Grafman, J., Sadato, N., Wachs, J., \& Hallett, M. (1995). Brain activation during the generation of non-emotional and emotional plans. NeuroReport, 6, 1269-1272.

Peterson, B. S., Skudlarski, P., Gatenby, J. C., Zhang, H., AnderSon, A. W., \& Gore, J. C. (1999). An fMRI study of Stroop wordcolor interference: Evidence for cingulate subregions subserving multiple distributed attentional systems. Biological Psychiatry, 45, 1237-1258.

RusSELL, J. A. (1978). Evidence of convergent validity on the dimensions of affect. Journal of Personality \& Social Psychology, 36, 1152-1168.

Russell, J. A. (1980). A circumplex model of affect. Journal of Personality \& Social Psychology, 39, 1161-1178.

Schaefer, S. M., Jackson, D. C., Davidion, R. J., Aguirre, G. K., KimberG, D. Y., \& Thompson-Schill, S. L. (2002). Modulation of amygdalar activity by the conscious regulation of negative emotion. Journal of Cognitive Neuroscience, 14, 913-921.

Shimamura, A. P. (2000). The role of the prefrontal cortex in dynamic filtering. Psychobiology, 28, 207-218.

Simpson, J. R, Drevets, W. C., Snyder, A. Z., Gusnard, D. A., \& RAICHLE, M. E. (2001). Emotion-induced changes in human medial prefrontal cortex: II. During anticipatory anxiety. Proceedings of the National Academy of Sciences, 98, 688-693.

Simpson, J. R., Ongur, D., Akbudak, E., Conturo, T. E., Ollinger, J. M., Snyder, A. Z, Gusnard, D. A., \& Raichle, M. E. (2000). The emotional modulation of cognitive processing: An fMRI study. Journal of Cognitive Neuroscience, 12, 157-170.

Stormark, K. M., Nordby, H., \& Hugdahl, K. (1995). Attentional shifts to emotionally charged cues: Behavioural and ERP data. Cognition \& Emotion, 9, 507-523.

Talairach, J., \& Tournoux, P. (1988). Co-planar stereotactic atlas of the human brain (2nd ed.). Stuttgart: Thieme. 
Taylor, S. F., Kornblum, S., Lauber, E. J., Minoshima, S., \& KoEPPE, R. A. (1997). Isolation of specific interference processing in the Stroop task: PET activation studies. NeuroImage, 6, 81-92.

Teasdale, J. D., Howard, R. J., Cox, S. G., Ha, Y., Brammer, M. J., Williams, S. C. R., \& Checkley, S. A. (1999). Functional MRI study of the cognitive generation of affect. American Journal of Psychiatry, 156, 209-215.

Thompson-Schill, S. L., D'Esposito, M., Aguirre, G. K., \& Farah, M. J. (1997). Role of left inferior prefrontal cortex in retrieval of semantic knowledge: A reevaluation. Proceedings of the National Academy of Sciences, 94, 14792-14797.

Toglia, M. P., \& Battig, W. F. (1983). Handbook of semantic word norms. Hillsdale, NJ: Erlbaum.

Van Strien, J. W., \& Heist, R. (1995). Altered visual field asymmetries for letter naming and letter matching as a result of concurrent presentation of threatening and nonthreatening words. Brain \& Cognition, 29, 187-203.

VAn Strien, J. W., \& Morpurgo, M. (1992). Opposite hemispheric activations as a result of emotionally threatening and non-threatening words. Neuropsychologia, 30, 845-848.

Watson, D., Wiese, D., Vaidya, J., \& Tellegen, A. (1999). The two general activation systems of affect: Structural findings, evolutionary considerations, and psychobiological evidence. Journal of Personality \& Social Psychology, 76, 820-838.

Whalen, P. J., Bush, G., McNally, R. J., Wilhelm, S., McInerney, S. C., JeniKe, M. A., \& RAUCH, S. L. (1998). The emotional counting Stroop paradigm: A functional magnetic resonance imaging probe of the anterior cingulate affective division. Biological Psychiatry, 44, 1219-1228.

Williams, J. M. G., Mathews, A., \& MacLeod, C. (1996). The emotional Stroop task and psychopathology. Psychological Bulletin, 120, 3-24.

\section{NOTE}

1. The reason for including four additional color words beyond the four that were directly response competing is related to two constraints on the experimental design. First, we were limited to four responses (ink colors) due to a four-button response pad, and thus only four color words could be directly response competing. At the same time, we wanted to increase the number of emotion words as much as possible, to avoid excessive repetitions of individual words, while still keeping the number of emotion words the same as the number of color words, for the best comparability between the two tasks. Thus, we increased the set size to eight words for all word sets, leading to the need for additional color words.

\section{APPENDIX \\ Word Lists}

Negative, high arousal: danger, fear, hate, hell, pain, panic, scream, stress

Negative, low arousal: dreary, failure, gloom, lonely, misery, pity, sad, unhappy

Positive, high arousal: arouse, desire, ecstasy, excite, intimate, lust, romantic, sex

Positive, low arousal: bless, comfort, gentle, heal, kind, peace, safe, trust

Color word eligible: red, blue, yellow, green, scarlet, navy, gold, emerald

Color word ineligible: gray, purple, tan, orange, charcoal, violet, brown, peach

Neutral: data, equal, function, graph, odd, prime, root, sine; century, decade, era, hour, minute, month, time, year; add, divide, integer, math, multiply, number, subtract, sum; dawn, day, evening, morning, night, noon, today, tomorrow; bank, bond, deposit, fee, lend, loan, mortgage, sell; ballot, bill, council, court, hearing, judge, jury, law

(Manuscript received August 27, 2002;

revision accepted for publication February 28, 2003.) 